This is an Accepted Manuscript of an article published by Taylor \& Francis in Policy and Practice in Health and Safety on 18/06/2020, available online: https://www.tandfonline.com/doi/full/10.1080/14773996.2020.1777799 


\section{Safety Climate Factors in Construction - A Literature Review}

Tariq Umar

A'Sharqiyah University,

P.O Box 42, Ibra, Oman. 400.

E-mail: tariqumar1984@gmail.com

Tel: +96896381864 


\section{Abstract:}

It is an established fact that a mature safety climate and a rich safety culture contribute to achieving a safe workplace. This paper aims to explore and to make explicit the existing safety climate assessment tools and dimensions and suggests the leading factors that can be used for safety climate assessment in construction. The construction industry and the status of occupational safety and health are firstly discussed in a global context. The concept of safety climate is then discussed with a review of different safety climate factors from the published literature. A qualitative research method was employed to explore the existing safety climate factors. A total of 19 safety climate assessment tools with 103 safety climate factors spanning over a period of 39 years $(1980-2019)$ are discussed. The most prevailing safety climate factors including management commitment, training, employees' involvement, behavior, communication, accountability and justice, and leadership are discussed in the paper. It is recommended that the factors discussed in this paper may need to be validated first before they are incorporated in the assessment of the safety climate of a specific construction project and organization in a country or region.

Keywords: Health \& Safety, Management, Safety \& hazards, Safety Climate, Assessment, Construction Industry, Safety Climate Factors.

\section{Introduction:}

Occupational and safety-related expenditures result in a huge cost and considered an additional burden on the economy of the countries. A press release of the International Labour Organization shows an estimate of occupational safety and health-related issue cost an annual amount of $4 \%$ to the world gross domestic product (ILO, 2013). For the year 2018, the world gross domestic product was estimated at US \$ 87.51 trillion, thus the cost of occupational safety and health-related factors for the same year can be around the US \$ 3.5 trillion. It is difficult to gauge the cost of accidents involving injuries and deaths resulting from poor occupational safety and health condition as these have multiple implications. Umar and Egbu (2018a) while discussing the root causes of accidents noted that there are five main stakeholders associated with accidents at the workplace. These stakeholders include the affected workers itself, the family and friends of those workers, the co-workers, the employer, and society. All these stakeholders have to bear the costs of poor occupational safety and health conditions for a long period of life. Many researchers have conducted their research around the causes of accidents, thus the causes of accidents in different industries are well known and preventable in most cases (Umar and Egbu, 2018-b). Different studies have shown that the cost of an accident could more than the cost of prevention; however many organizations don't have such awareness thus they remain reluctant to spend on the problems such as accidents that don't arise more frequently (Umar et al, 2018-a). Similarly, safety and health-related factors don't get priority in many organizations and get the least attention from managers as reported by Umar and Wamuziri (2016). The model for improving the safety performance of construction organizations in Oman presented by Umar and Wamuziri (2016) also stresses on the awareness of the benefits of improved safety performance. Similarly, health factors such as body mass index, blood pressure and heart rate are also considered important in relation to the safety and productivity of workers (Umar et al., 2018-b).

The construction industry is growing rapidly in all countries and recognized as the main source for providing jobs to different workers globally. It is expected that the global construction industry will reach 14 trillion US\$ in 2025 which was 9.5 trillion US\$ in 2014, reflecting an overall growth of $67 \%$ as shown in figure 1(Statista, 2017). In the Gulf Cooperation Council (GCC) member countries, the economy is heavily reliant on oil and grad export and contributes up to $50 \%$ of the total gross domestic product (GDP) (Umar and Wamuziri, 2017). In recent years, the dip in oil and gas prices somehow has affected the GCC construction industry as well (Umar and Egbu, 2018). A comparison of the contract awarded in the GCC countries, in the first quarter of 2017 and 2018, therefore, shows an overall decline of US \$ 5.0 Billion (Ventures, 2018). The construction contract awarded in the first three months of 2017 and 2018, in GCC countries is shown in figure 2. While there is an impact on the construction industry due to the 
overall economic situation, different studies have shown that the construction industry will be growing in the near future. Umar et al., (2018-a) while discussing the occupational safety and health regulations in Oman, reported that the value of the construction industry in Oman will grow to 6.88 Billion Omani Rial by 2026, which was 2.26 Billion Omani Rial in 2016 (Umar et al., 2019). Moreover, the construction GDP in Oman is forecast to grow to $15.4 \%$ of the total GDP by 2026. Overall, they reported that the construction growth rate is forecasted to be at peak in 2020 (figure 3).

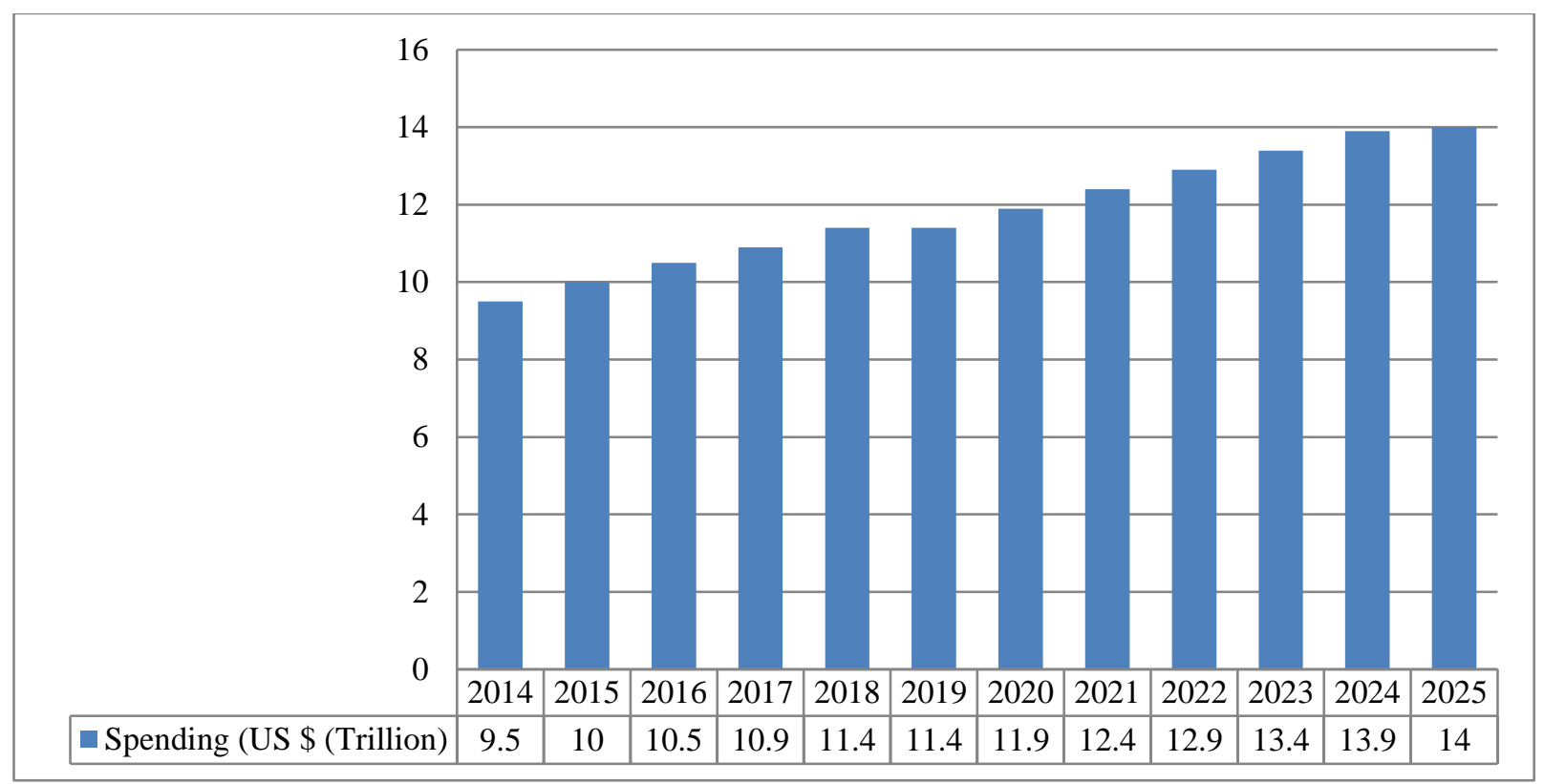

Figure 1: Global Construction Industry Growth (Statista, 2017).

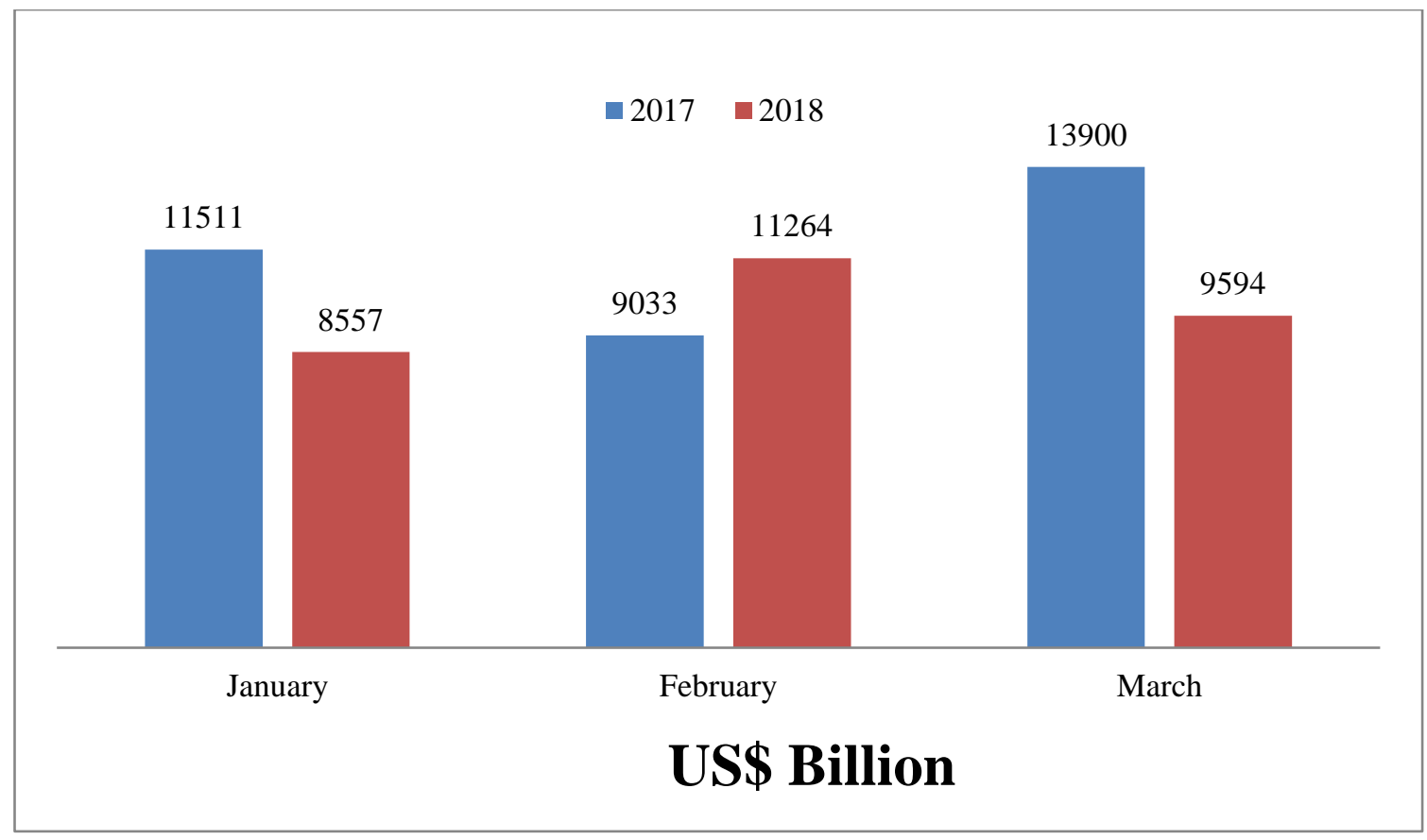

Figure 2: Comparison of Awarded Construction Contracts In GCC (Ventures, 2018). 


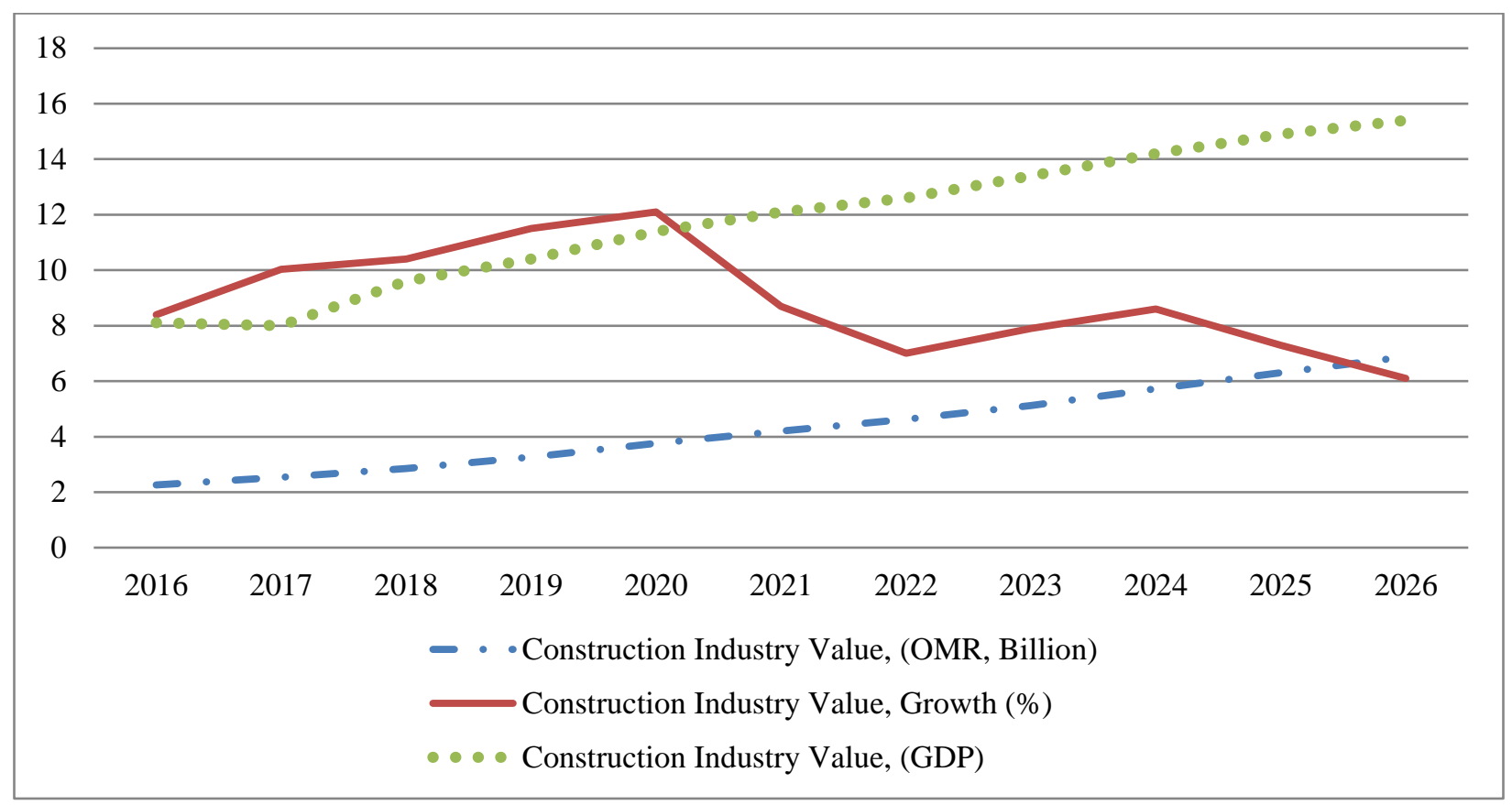

Figure 3: Oman Infrastructure and Construction Industry Forecasts (2016-2026).

With all this growth and improvement in the construction industry, it is also regarded as the second most hazardous industry after manufacturing. If it is considered that the occupational safety and health-related costs will be $4 \%$ of the total costs of the construction projects in 2018, the total costs of occupational safety and health will thus be equal to the US \$ 0.456 trillion. Similarly, Umar (2016) reported the cost of accidents in the Omani construction industry considering two criteria using the available data which includes the number of workers in the construction industry and the value of construction projects in a financial year. He concluded that the compensation costs of accidents are to be 3.74 million/year based on the number of workers in the construction industry. The reported costs of accidents based on the value of construction projects were estimated at US\$ 3.237 billion. The International Labour Organization data for the year 2015 indicate that every year 108,000 workers died on construction sites due to different occupational safety and health conditions. In the developing world, There are higher risks (3 6 times more) of death linked with construction work in developing countries (ILO, 2015). Although there is no organization in Oman that collects and analyzes construction accidents, different studies have shown that these accidents result in a huge cost to the Omani economy (Umar and Wamuziri, 2016). For instance, Umar et al. (2018) while considering the occupational safety and health regulations in Oman reported that the accidents related expenditures in Oman rose from 1 Million OMR (=2.6 Million US\$) in 2012 to 2.9 Million OMR (=7.53 Million US\$) in 2016, reflecting an increase of 1.9 Million OMR in five years or 0.38 Million OMR in one year. Similarly, Umar and Egbu (2018-a), while evaluating the main causes of accidents in construction in Oman, reported a total of 623 different types of accidents that took place in only one project as shown in table 1. This project's estimated budget was the US \$ 305.90 Million and there many similar projects in the execution stage that time, however, the authors were not able to obtain the accident data in these projects due to several reasons. First of all, there is no organization in Oman that aimed to collected and analyzed the construction accidents in Oman on regular basis, and secondly, construction organizations reluctant to the public their record of accidents as they feel this may affect their organization's reputation. Similarly, another research study which aimed to investigate the causes of the delay in construction projects in Oman reported the accidents at the site as one of the main causes of delay in construction projects (Umar, 2018). 


\begin{tabular}{|c|c|c|c|c|c|c|}
\hline Year & $\begin{array}{l}\text { Property / } \\
\text { Equipment } \\
\text { Damage }\end{array}$ & $\begin{array}{l}\text { Alternate } \\
\text { Work Injury } \\
\text { (AWI) }\end{array}$ & $\begin{array}{l}\text { First Aid } \\
\text { Injury } \\
\text { (FAI) }\end{array}$ & $\begin{array}{l}\text { Loss Time } \\
\text { Injury } \\
\text { (LTI) }\end{array}$ & $\begin{array}{l}\text { Medical } \\
\text { Treatment } \\
\text { Injury (MTI) }\end{array}$ & Total \\
\hline 2011 & 0 & 0 & 0 & 0 & 0 & $\mathbf{0}$ \\
\hline 2012 & 7 & 1 & 1 & 0 & 2 & $\mathbf{1 1}$ \\
\hline 2013 & 155 & 0 & 3 & 3 & 4 & $\mathbf{1 6 5}$ \\
\hline 2014 & 164 & 2 & 0 & 5 & 5 & $\mathbf{1 7 6}$ \\
\hline 2015 & 179 & 2 & 7 & 1 & 4 & $\mathbf{1 9 3}$ \\
\hline 2016 & 75 & 0 & 3 & 0 & 0 & $\mathbf{7 8}$ \\
\hline Total: & $\mathbf{5 8 0}$ & $\mathbf{5}$ & $\mathbf{1 4}$ & $\mathbf{9}$ & $\mathbf{1 5}$ & $\mathbf{6 2 3}$ \\
\hline
\end{tabular}

Table 1: Different Types of Accidents in a Construction Project in Oman

Considering all these challenges associated with safety and health in the construction industry, many researchers have proposed solutions on how to overcome them by improving the safety and wellbeing of the peoples working in this industry. These solutions cover the incorporation of safety in all stages of a construction project from design until the demolition of the project. A study conducted by Bong et al., (2015) investigated the role designer in workplace health and safety in the construction industry of South Africa and concluded that Designers are aware of the hazards on sites and design firms are willing to embrace the guidelines if they are protected from liability. Umar (2016-b) while defining the safety leadership in construction stressed the key attributes of safety leadership and noted that without a clear definition towards safety leadership, a misalignment between safety expectations may occur which can create a misappropriation towards safety efforts. In the last two decades, the appreciation and importance of administrative, managerial and social factors for an improved safety performance have significantly increased. The focus on the safety culture and safety climate has been expended. This article presents the research on using the safety climate approach to improve safety performance in construction organizations. There have been a number of safety climate tools developed by many researcher and organizations which have been used in different industries. The varieties of the existing safety climate tools and factors could cause confusion among the decision-makers when they wish to use a specific tool or factor. The level of such confusion could be greater in the construction industry as most of the existing tools have been developed focusing on other industries such as manufacturing. This research, therefore, aims to review the existing safety climate factors used in different safety tools since 1980 and identify the most prevailing factors that can be used in the construction industry of Oman. The safety climate factors identified in this research will help decision-makers especially those from the construction industry, to choose the most appropriate safety climate factors for the assessment of the safety climate of their organization or project. The terms of safety culture and safety climate are first discussed in the next section. The safety climate tools developed by different researchers and organizations in the past 38 years (1980-2018) have been identified using an internet search considering the Preferred Reporting Items for Systematic Reviews and Meta-Analyses (PRISMA) flow diagram described by Moher et al., (2009). This model required a transparent step by step approach to being adopted in the qualitative or quantitative analysis. These steps include identification, screening, eligibility and final inclusion of the studies considered in the analysis. The safety climate factors used in these tools are discussed in the later section with a specific reference to the construction industry.

\section{Safety Climate and Safety Culture:}

The focus on elements that impact safety and safety improvements within organizations has been significantly shifted in the last century. Scientists and experts have established the safety culture and safety climate as fundamental elements in curtailing injuries, illnesses and deaths at the workstation. 
Safety climate may be classified as a subgroup of organizational climate which provides a direction to safety management, complementing the frequent predominant engineering path. An understanding of the safety climate elements can be helpful in improving the safety performance of a construction organization. Additionally, safety climate findings are regarded to be more precise (e.g. multi-sliced) and provide pro-active ground for improving safety, rather than reactive (after the fact) in which data from accident numbers and accident and incident investigations are used (Seo et al., 2004). Hale and Hovden (1998) define three periods of safety which include the technical period (1920's), the human factor period (1970's) and the management system period (1980's). The third period of safety spread-out the attention to include safety culture and safety climate. The approach of safety culture was accurately presented and delineated after the Chernobyl accident which took placed in 1986 (INSAG, 1992). Thus, enthusiasm in the approach of safety culture has been significantly increased as safety researchers and practitioners have solicited to characterize and operationalize this approach (Clarke, 2000). One of the reasons for this is that rich safety culture and a mature safety climate are considered among the most important elements in attaining a safe workplace (Bergh et al., 2013). To enhance the level of safety culture and safety climate, it is crucial to, first gauge the existing level of safety culture and safety climate, then agree what level of safety culture and safety climate is required, obtainable and desired, and then to make strategies to accomplish the safety culture and safety climate, which is desired (AIChE, 2012).

The safety climate can be defined as common understandings between the employees of a social unit, of policies, procedures, and practices connected to safety in a business ((Kines, et al., 2011). The Centre for Construction Research and Training (CPWR) defined safety climate as workgroup members' common thoughts of management and workgroup safety-related policies, procedures and practices (CPWR, 2014). Many construction organizations are trying to enhance their safety climate dimensions as a way to step closer to the target of obtaining zero accidents at workplaces (CPWR, 2014). Similarly, Zohar (1980) described the safety climate as a view of workers' understandings about the respective significance of safer acts in their work-related behavior. There are several definitions of safety culture endorsed by many researchers; however, the Cox and Cox (1991) definition appear to be more concise and simple. They described safety culture, as the attitudes, beliefs, understandings, and values that employees contribute in connection to safety. Scientists and experts have established safety culture and safety climate as fundamental elements in curtailing injuries, illnesses and deaths at workstations. A recent study conducted by Chan et al. (2017-a) considering the Hong Kong construction industry with an increasing number of ethnic minority workers, concluded that the safety climate is significantly associated with the degree of safety participation and safety compliance. Similarly, Umar et al. (2017-b) in their research on the factors that influence safety climate in construction concluded that it is important to involve all the team members of construction project including the managers, engineers, supervisors and workers to ascertain the factors that may have a high influence on safety climate in a local context. A study on safety climate which targets only a specific occupational group in construction will, therefore, represent only the view of that particular group and thus cannot be considered as a view of the whole construction team. Any safety climate assessment tool developed on such studies will provide misleading results and will mislead the decision-makers. The process of using a safety climate assessment tool to improve safety performance in construction organizations as described by Umar and Wamuziri (2017) is shown in figure 1. The concept of using the safety climate approach in Gulf Cooperation Council (GCC) member countries was first truly discussed by Umar and Wamuziri (2017). Umar and Egbu (2018) reported different safety climate factors relevant to the construction industry in Oman. The main drawback of this study was that the data was only collected from a small number of respondents using a semi-structured interview approach. The only justification for using this approach of research with a limited number of respondents mentioned by the authors was the nature of study which they claimed as exploratory. Similarly, the study on the safety climate conducted by Schwatka et al., (2016) considered only the article published from 2008 to 2014. One of the main drawbacks of this research was that approximately $80 \%$ of the studies that passed the inclusion criteria for the research were published in 2008. This meant that much of the work was based on studies carried out in 6 years from 2008 to 2014. This is particularly important when we already know that the period considered in the research was not consistent with the 
periods of safety defined by Hale and Hovden (1998). A similar problem was also observed in the study carried out by Alruqi et al., (2018). In their meta-analysis approach, they have finally included 11 studies in their study. These 11 studies were carried out during the period of 2003 to 2014. Must of the studies included in the research were from the same author or the group of authors. For instance, 4 out of 11 studies included in the meta-analysis were authored by Lingard (Lingard et al., 2012; Lingard et al., 2011; Lingard et al., 2010-a; Lingard et al., 2010-b). Two of the remaining studies were authored by Hon in 2014 (Hon et al., 2014-a; Hon et al., 2014-b). Only two papers (18\%) considered in this research were published in 2003, remaining of then (9 out of $11=82 \%$ ) were published from 2010 to 2014. Thus clearly, the results presented in this research appeared to have significant limitations in terms of period coverage and the selection of studies. The research presented in this paper, therefore, aimed to overcomes these limitations and produce a literature review on the safety climate which covers the required period and the studies relevant and important to safety climate. The next section describes the method adopted to identify the main safety climate assessment tools developed in the past 38 years spanning from 1980 2018. In the later section, the safety climate factors or dimensions used in these tools are discussed.

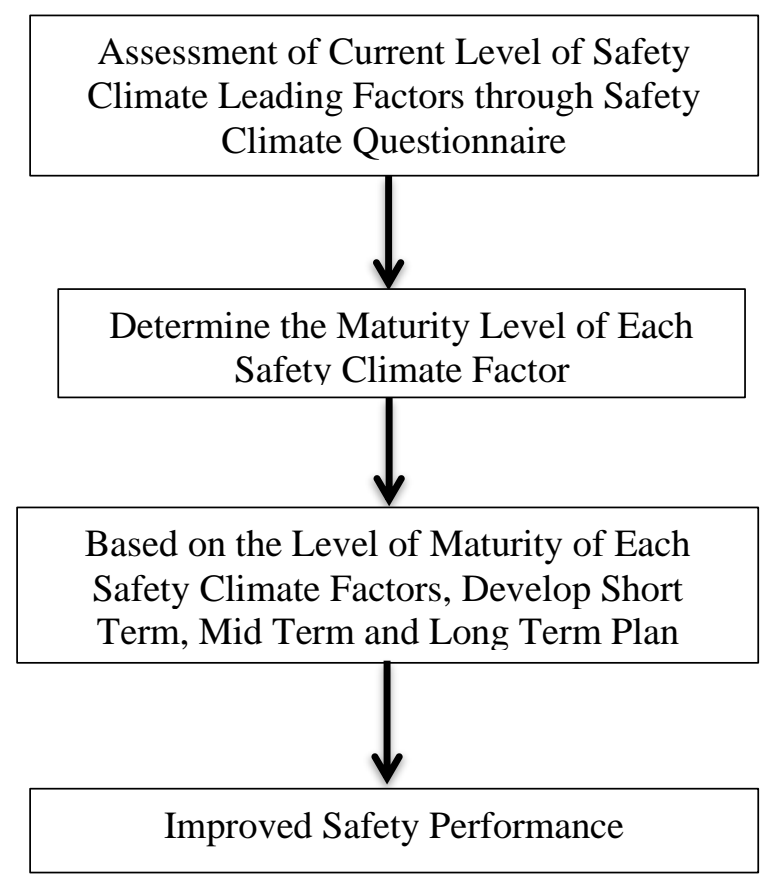

Figure 4. Process of Using Safety Climate to Improve Safety Performance (Umar and Wamuziri, 2017).

\section{Research Methodology:}

The research methods in social science are commonly classified as quantitative or qualitative. Quantitative research stresses quantification in data collection and examination. It takes a deducible way to the connection among theory and research and stress are kept on the confirmation of theories. The quantitative research method integrates the norms and practices of the natural scientific model and positivism. It views the social phenomenon as an outer objective truth (Cooper et al., 2006). On the other side, a qualitative research approach stresses on words and contexts despite quantification in data 
collection (Opdenakker, 2006). It stresses an introductory approach in the relationship between theory and research and focus is settled on the formation of theories. The majority of the researchers prefer to incorporate both qualitative and qualitative methods, referred to as combined research methods and highly appreciated in the literature due to certain advantages (Umar and Egbu, 2018). The research, however, presented in this paper is somehow exploratory in nature; therefore a qualitative method with limited use of the quantitative method was considered to be a more suitable method for data collection. The process of the research adopted here was guided by Bryman (2016) as shown in figure 5.

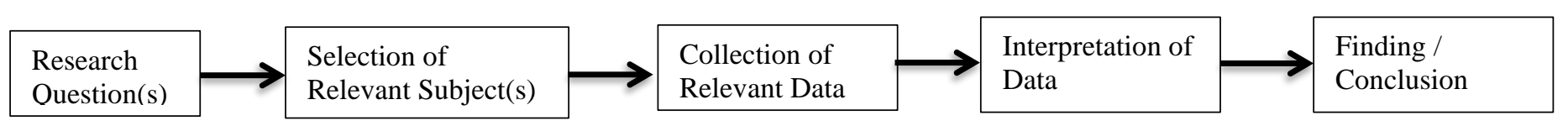

\section{Figure 5. Process of Qualitative Research}

Bryman (2012) while describing the different research methods related to the qualitative research outlined one of the methods as the collection of qualitative analysis of texts and documents. He further explained that websites and webpages can be the potential and reliable sources for both quantitative and qualitative research methods. The main research question for this research was the simple one "what is the most common safety climate factors used in safety climate assessment tools". To collect the relevant data, an internet search was employed. Since it was revealed from the literature review that in the last 40 years, the topic of safety climate and safety climate assessment tools have therefore attracted the attention of researchers in construction management. Clearly, a huge work in the area of safety climate was carried out since 1980, which was defined as a management system period by Hale and Hovden (1998). This was the period of safety which results in the inclusion of safety culture to the safety management system. The approach of safety culture was accurately presented and delineated after the Chernobyl accident which took placed in 1986 (INSAG, 1992). Thus for search criteria, the period of 1980-2018, spanning over a period of 38 years was selected. Two terms "safety climate assessment tools" and "safety climate factors" were used for the search purpose. For screening purpose, only the safety climates factors and tools which were used in construction, utilities and oil and gas sectors were selected. The utilities and oil and gas sectors were considered due to the reasons which reflect some similarity between the nature of the work in the construction and these sectors. For instance, out of 500,000 workers in the oil and gas industry, more than 30,000 workers are doing construction and extraction related tasks. Because these workers perform similar nature of work as they do in the construction industry, they face the same occupational safety hazards as they encounter in the construction sectors (MCR Safety, 2019). Similarly, Bodner et al., (2014) noted that because utility and construction work requires physical stamina and involves irregular hours and exposure to weather, dangerous tools, and equipment, such workers are significantly more prone to injury than other workers from different industries. Further screening was done using the number of Google citations in case the tool or safety climate factors were developed or identified in a research paper. This screening criterion was however not applied to the tools or safety climate factors that were developed or identified by international health and safety organizations or associations. To ensure that a systematic review process is adopted in this study, the research method for the review was guided by Preferred Reporting Items for Systematic Reviews and Meta-Analyses (PRISMA). The PRIMA guidelines required to follow a four steps process to include the final of studies in the systematic review and meta-analysis. These steps include the Identification, Screening, Eligibility and Inclusion of the existing studies. The full flow diagram with the results of the PRISMA used in this research is given in figure 7 of the next section. The research method used in this part of the research is further explained in figure 6 . 


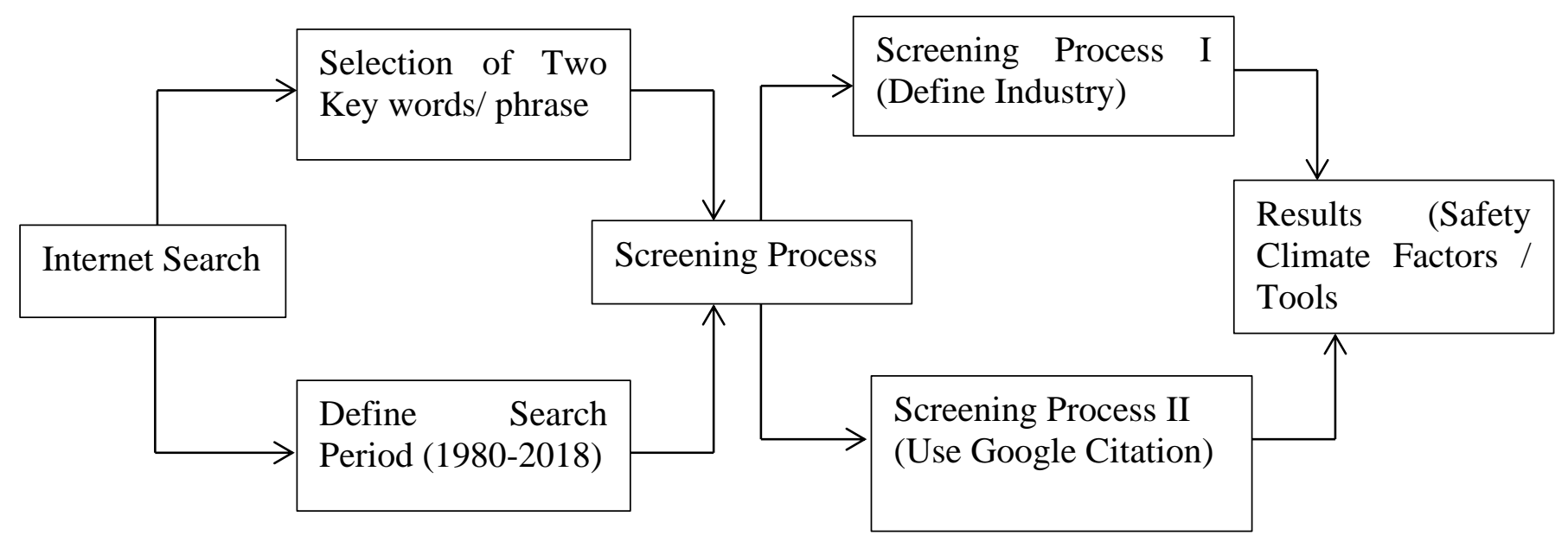

Figure 6: Description of Research Methodology (Internet Search)

\section{Results and Discussion:}

The initial internet search using google scholar resulted in a huge number of results for the two terms "safety climate assessment tools" $(n=353,000)$ and "safety climate factors" $(n=1,470,000)$. Since the focus of this research was on safety climate assessment tools and on the safety climate factors used in these tools, therefore the search results from the term "safety climate assessment tools" $(\mathrm{n}=353,000)$ were considered for further processing. The PRISMA flow diagram was followed to narrow down the results and to determine the final studies (n) for inclusion in this research as shown in figure 7. In the first step of the screening process, duplicates items $(=261,750)$ from the search were removed which reduced the number to 88,250 . In the next screening process, google citation for the studies $(\mathrm{n}=88,250)$ was used. At this stage, a total of 66,188 studies were excluded from the list considering that these studies were having a citation index of less than 50 . The citation criteria were however not implemented on the papers published in recent years. This brought the number of valid studies to 22,062 for this study. A total of 129 articles were assessed for eligibility and 21,933 were excluded from the fact that either these articles were based on the existing studies already included in the eligible articles or the authors were not able to access these articles. The eligible articles $(n=129)$, when further reviewed, were found that the safety climate factors used in these articles were almost the same. It was, therefore, and then decided to include the top leading articles based on the number of their citations. Some of the studies included in this research were not directly linked to the construction industry; however, these studies have provided a foundation for the development of safety climate tools not only for construction but also for other industries. Such studies have been highly recognized in the construction industry. For instance, the study conducted by Zohar in 1980 has reached to citations of 3097 (Google Scholar as of $4^{\text {th }}$ January 2020). This research is therefore cited in all studies related to safety climate. Similarly, the number of citations of the study carried out by Neal et al., (2000) has reached 1718 (Google Scholar as of 4th January 2020). In their study, they have looked into the impact of organizational climate on safety climate. Such an impact can be irrespective of the type of organization, therefore the finding can be applied to construction organizations as well. This was evident when it has been noted that both the studies conducted by Zohar (1980) and Neal et al., (2000) were well cited in the safety climate tools developed. For instance, the study related to review of safety climate in construction conducted by Schwatka et al., (2016) included both the studies carried out by Zohar (1980) and Neal et al., (2000). This is the case with all other studies reported in this research. The final articles from which the safety climates factors are derived in this research thus stand at 19 as 
shown in table 2. Briefly, the number of assessment tools found through internet search was one in each year 1980, 1991, 1997, 2004, 2005, 2006, 2010 and 2016. There were two safety climate assessment tools in 2000 and 2008, three assessment tools found in 2011 and one assessment tool in 2017, one in 2018 and two in 2019. The numbers of leading safety climate factors used in these assessment tools were 90 . The result shows that in the first 19 years from 1980 to 1999 only three (15.78\%) safety climate assessment tools were developed. In the next phase of 19 years from 2000 to 2019, the number of safety climate assessment tools was $16(84.21 \%)$. There were two safety climate assessment tools $(10.56 \%)$ which were not divided into factors or dimensions, while the remaining safety climate tools $(89.47 \%)$ were divided into factors or dimensions ranging from 2 to 8 factors in each tool. This somehow reveals that it is most common among the safety science researchers to divide the safety climate assessment tools into factors or dimensions. The most common factors used in these tools were;
a) Management or Organizational Commitment towards Safety
b) Safety Training
c) Employees Involvement in Safety
d) Workers Safety Behavior
e) Safety Communication
f) Safety Accountability and Justice
g) Supervisory Leadership 

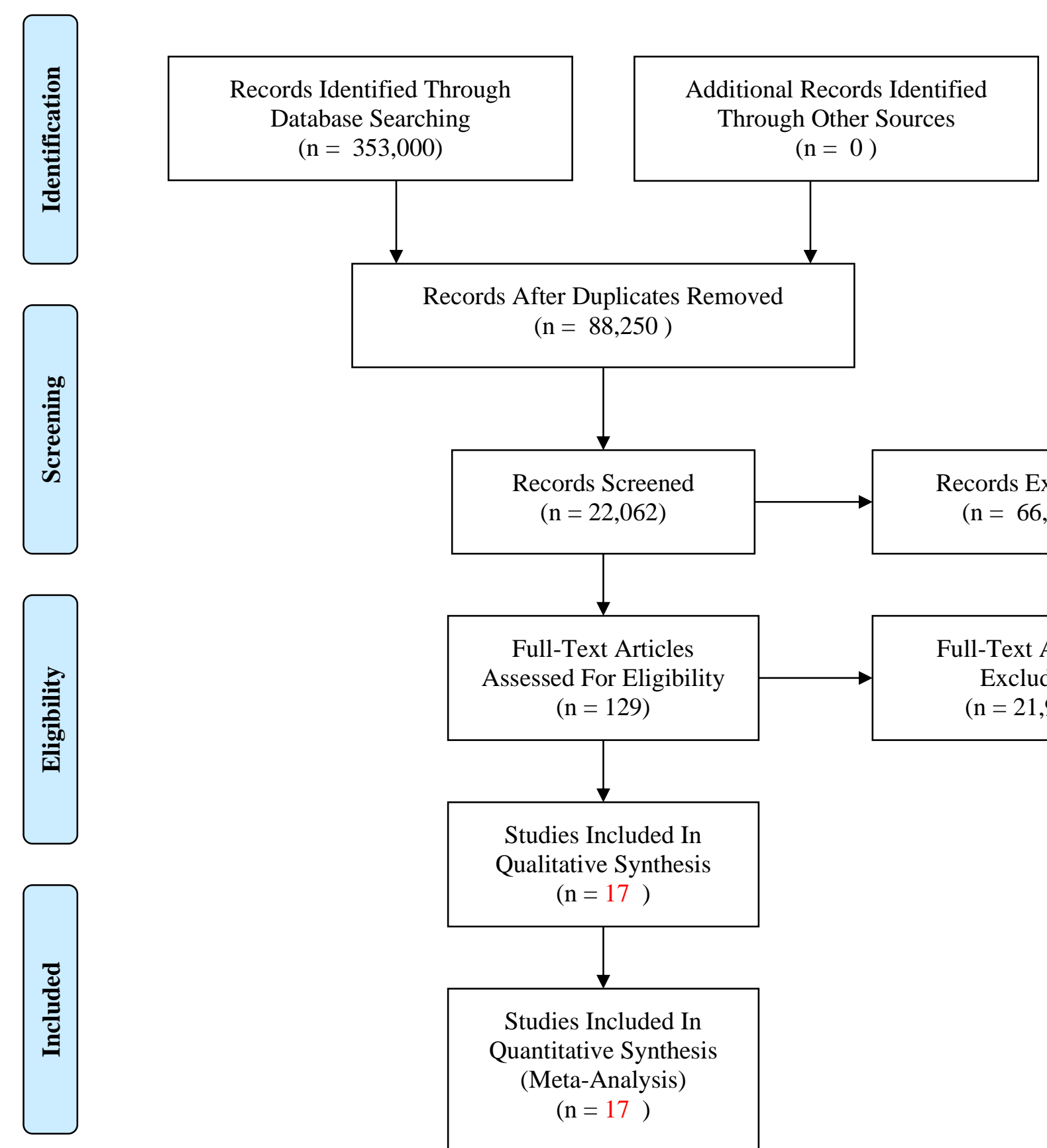

$$
(\mathrm{n}=88,250)
$$

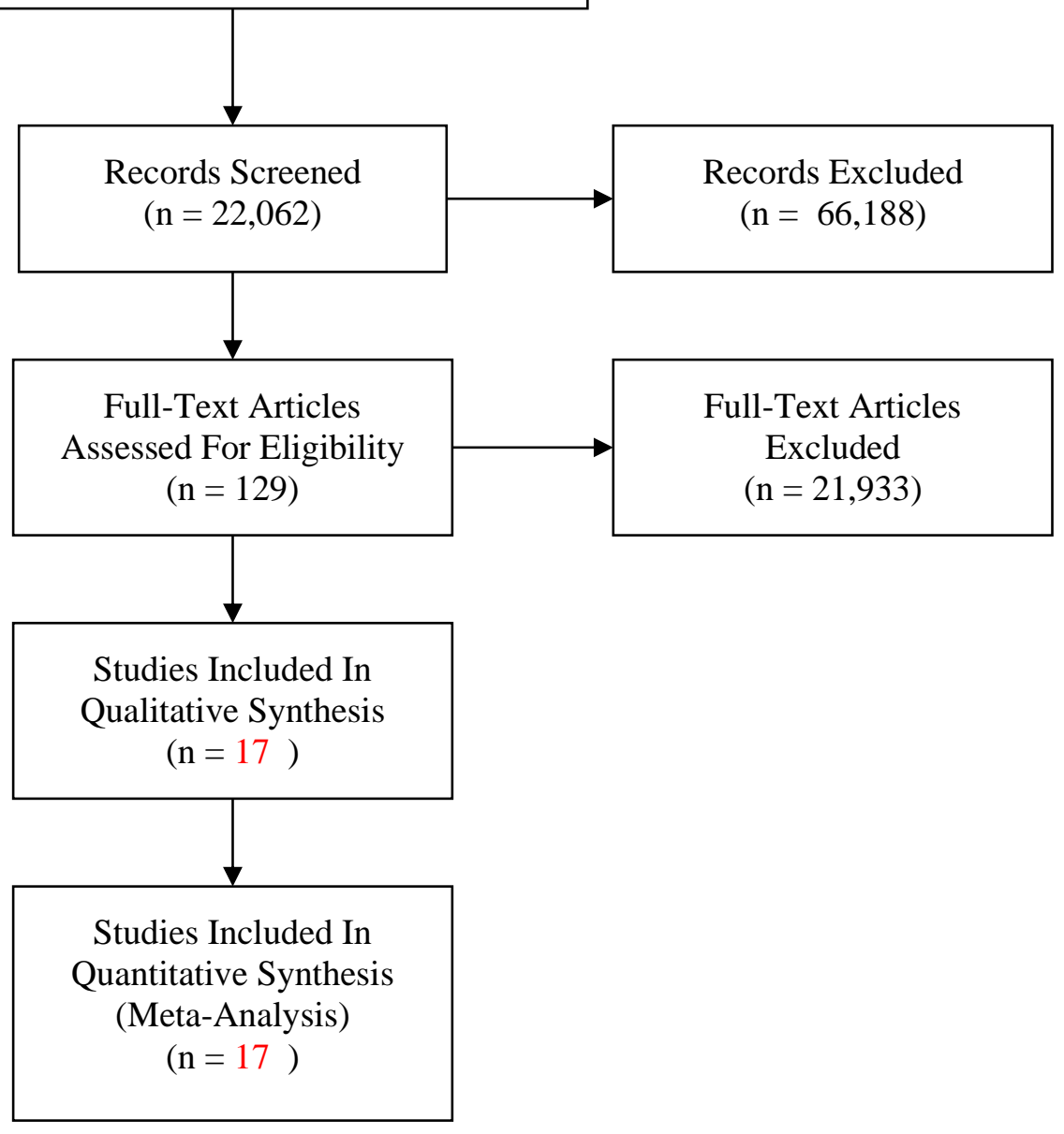

Figure 7: PRISMA Flow Diagram Adopted in the Research 


\begin{tabular}{|c|c|}
\hline $\begin{array}{l}\text { Safety Climate Assessment } \\
\text { Tool }\end{array}$ & Safety Climate Factors / Dimensions \\
\hline Zohar (1980) & $\begin{array}{l}\text { (i) Management attitude toward safety; (ii) Work pace and safety; (iii) Effects of } \\
\text { safe conduct on promotion; (iv) Effect of safe conduct on social status; (v) } \\
\text { Perceived risks; (vi) Perceived importance of safety training; (vii) Perceived status } \\
\text { of safety officer; (viii) Perceived status of safety committee }\end{array}$ \\
\hline $\begin{array}{l}\text { Dedobbeleer and Beland } \\
\text { (1991) }\end{array}$ & (i) Management commitment; (ii)Worker involvement \\
\hline HSE (UK) (1997) & $\begin{array}{l}\text { (i) Organizational commitment; (ii) Health and Safety oriented behavior; (iii) } \\
\text { Health and Safety Trust; (vi) Usability of Procedures; (v) Engagement in health } \\
\text { and safety; (vi) Peer group attitude; (vii) Resources of health and safety (viii) } \\
\text { Accidents and near miss reporting }\end{array}$ \\
\hline Neal et al. (2000) & $\begin{array}{l}\text { (i) Management values; (ii) Communication; (iii) Training; (iv) Physical Work } \\
\text { Environment; (v) Safety Systems; (vi) Knowledge; (vii) Motivation; } \\
\text { (viii)Behavior }\end{array}$ \\
\hline Mohamed, (2002) & $\begin{array}{l}\text { 1. Commitment; (ii); Communication; (iii) Safety rules and procedures; (iv) } \\
\text { Supportive environment; (v) Supervisory environment; (vi) Workers' } \\
\text { involvement; (vii) Personal appreciation of risk; (viii) Appraisal of work hazards; } \\
\text { (ix) Work pressure; (x) Competence }\end{array}$ \\
\hline Seo et al. (2004) & $\begin{array}{l}\text { (i) Management commitment to safety; (ii) Supervisor safety support; (iii) } \\
\text { Coworker safety support; (iv) Employee participation in safety-related decision } \\
\text { making and activities; (v) Competence level of employees with regard to safety }\end{array}$ \\
\hline Zohar and Luria (2005) & $\begin{array}{l}\text { (i) Active practices (monitoring, enforcing); (ii) Proactive practices (promoting } \\
\text { learning, development); (iii) Declarative practices (declaring, informing); (iv) } \\
\text { Active practices (Monitoring, controlling); (v) Proactive practices (Instructing, } \\
\text { Guiding); (vi) Declarative practices (Declaring, Informing) }\end{array}$ \\
\hline Parker et al. (2006) & (i) Concrete organizational aspects; (ii) Abstract organizational concepts \\
\hline Pousette et al. (2008) & $\begin{array}{l}\text { (i) Management safety priority; (ii) Safety management; (iii) Safety } \\
\text { communication; (iv) Workgroup safety involvement }\end{array}$ \\
\hline CISCIS (2008) & $\begin{array}{l}\text { (i) Commitment and concern for Occupational Safety and Health by organization } \\
\text { and management; (ii) Resources for safety and its effectiveness; (iii) Risk taking } \\
\text { behavior and perception of work risk; (iv) Perception of safety rules and } \\
\text { procedures; (v) Personal involvement in safety and health; (vi) Safe working } \\
\text { attitude and workmates' influence; (vii) Safety promotion and communication }\end{array}$ \\
\hline Gittleman et al. (2010) & The tool is not divided in to factors or dimensions \\
\hline $\begin{array}{l}\text { Institute of Work and Health } \\
\text { (2011) }\end{array}$ & The tool is not divided in to factors or dimensions \\
\hline DeArmond et al. (2011) & (i) Safety compliance; (ii) Safety participation \\
\hline Kines, et al. (2011) & $\begin{array}{l}\text { (i) Management safety priority, commitment, and competence; (ii) Management } \\
\text { safety empowerment; (iii) Management safety justice; (iv) Workers' safety } \\
\text { commitment; (v) Workers' safety priority and risk non-acceptance; (vi) Safety } \\
\text { communication, learning, and trust in co-workers safety competence; (vii) Trust in } \\
\text { the efficacy of safety systems }\end{array}$ \\
\hline
\end{tabular}




\begin{tabular}{|l|l|}
\hline Schwatka et al. (2016) & $\begin{array}{l}\text { (i) General management commitment to safety; (ii) Safety policies, resources, and } \\
\text { training; (iii) Supervisor commitment to safety (iv) General organizational } \\
\text { commitment to safety; (v) Co-workers commitment to safety; (vi) Safety } \\
\text { communication; (vii) Worker involvement in safety; (viii) Risk appraisal and risk } \\
\text { taking }\end{array}$ \\
& $\begin{array}{l}\text { (i) Demonstrating management commitment; (ii) Aligning and integrating safety } \\
\text { as a value; (iii) Ensuring accountability at all levels; (iv) Improving supervisory } \\
\text { leadership; (v) Empowering and involving Employees; (vi) Improving } \\
\text { communication; (vii) Training at all levels; (viii) Encouraging owner/client } \\
\text { involvement }\end{array}$ \\
\hline CPWR (2017) & $\begin{array}{l}\text { (i) Supervisor's safety role; (ii) Management commitment to safety; (iii) Safety } \\
\text { rules and procedures; (iv) Individual responsibility to health and safety; (v) } \\
\text { Training }\end{array}$ \\
\hline Probst et al. (2019) & $\begin{array}{l}\text { (i) Demonstrating management commitment; (ii) Aligning and integrating safety } \\
\text { as a value; (iii) Ensuring accountability at all levels; (iv) Improving site safety } \\
\text { leadership; (v) Empowering and involving workers; (vi) Improving } \\
\text { communication; (vii) Training at all levels; (viii) Encouraging owner/client } \\
\text { involvement }\end{array}$ \\
\hline Kalteh et al. (2019) & $\begin{array}{l}\text { (i) Management and supervisor commitment to safety; (ii) Safety policies, } \\
\text { resources, and training; (iii) Co-workers involvement and commitment to safety; } \\
\text { (iv) Safety communication; (v) Priority for safety }\end{array}$ \\
\hline
\end{tabular}

\section{Table 2: Details of Safety Climate Assessment Tools Factors}

In the next section, these leading safety climate factors are discussed in detail.

\subsection{Management or Organizational Commitment towards Safety:}

One of the most common factors used in the identified safety climate tools can be referred to as management or organizational commitment towards safety. The first safety climate assessment tool designed by Zohar in 1980 was consist of 40 items covering eight different safety climate dimensions or factors and the first one was management attitude toward safety (Zohar, 1980). Management or organizational commitment toward safety can be displayed in a variety of ways. The literature review around management commitment suggests that in organizations where the number of accidents was low, top managers of that organization were found to be involved personally in all safety-related issues on a routine basis (Cohen et al. 1975; Zohar, 1980). On the other hand, a similar commitment was not evident in organizations with a high rate of accidents (Shafai-Sahrai, 1971; Cleveland et al. 1978; Zohar, 1980). In commercial organizations, the business priorities are informed through the top managers of that organization. Thus directly or indirectly these mangers are the main source of information related to the priorities and goals of such organizations (Kines et al. 2011). They further while quoting the organizational climate theories, noted that the worker's safety behavior is based on the organization's rules, policies, procedures, and practices. If in these rules, policies, procedures and practices safety gets priority, it will be reflected through workers' safe acts. Similarly, if safety remains one of the organizational priorities, it will be informed through the top managers of organizations which could be helpful in promoting a safe working environment. The results of this research show that "management commitment" is one of the main factors used in nine (70\%) different safety climate assessment tools. The finding of this research in terms of management commitment was aligned with the study on safety climate in the construction site environment conducted by Mohamed (2002) in which he ranked management commitment on the top of the list considering a total of 10 safety climate factors. Overall, the discussion 
suggests that organizational or management commitment has a major impact to promote safety culture in the organizations, thus needs to be considered as part of the safety climate assessment tool.

\subsection{Safety Training:}

Zohar (1980) while discussing and comparing the organizations with high accidents and low rates of accidents found that emphasize on safety training was the second factor that differentiates these organizations. Similarly, in mature organizations safety training for new workers was found to be an integral part of their orientation. In such organizations, follow up and periodic training of workers was carried out on a routine basis in these organizations (NSC, 1969; Cohen et al., 1975). A review of different safety climate tools conducted by Flin et al. (2000), observed that necessary safety training for workers was one of the main factors used in these tools. A research study carried out by Zahoor et al. (2016) related to occupational safety and health performance in the Pakistani construction industry, concluded that safety training was on the top of the most neglected factors. They further concluded that construction organizations that don't address the training issue could face a higher injury rate in their organizations. In construction projects, workers are expected to works with different machines and equipment during the execution cycle of the project. This it is important that such workers should have enough knowledge of the operation of these equipments. Umar and Egbu (2018-a) while finding the root causes of accidents in construction projects analyzed a total of 623 accidents in a highway project and noted that $14 \%$ of total accidents were caused by machines and equipments. Such accidents can only be reduced when workers have appropriate training which incorporates both operational and safety components of machines. The finding of the research conducted by Neal et al. (2000) emphasizes that apart from specific safety training (work-related), training which highlights the importance of safety has a greater effect to enhance the overall organizational climate. This fact was well established in a workshop organized by the Center to Protect Workers' Rights (CPWR) and The National Institute for Occupational Safety and Health (NIOSH) in the United States in June 2013. The aim of this workshop was to improve the understanding of the safety climate in construction (CPWR (2017). A total of 72 nominated construction stakeholders representing the broad of the industry participated in this workshop including, $25 \%$ representation from contracting organizations, $12 \%$ from employer associations, $14 \%$ from workers associations, $40 \%$ from researchers and academics, $6 \%$ from consulting organizations (6\%), and $4 \%$ from insurance companies. The participants concluded that safety training is one of the main factors of safety climate and needs to use in the assessment tools. In general, the observation leads to the conclusion that the safety climate of a construction organization or a construction project could not be completely measured without considering the factor of safety training.

\subsection{Employees Involvement in Safety:}

Employee's safety involvement refers to the activities undertaken by workers at the workplace which includes the assistance of colleagues, encouraging safety compliance at the workstation, demonstration of safety initiatives and attempt to enhance the safety performance at the workstation. The employee's perceptions related to safety risk and control can be directly linked to their participation and responsibility for safety. It has been evident by Walter and Haines (1988) that employees mostly give importance to the discrete responsibility when it comes to work associated safety and health matters. This finding further appears to be consistence with the finding of Frenkel et al. (1980) and Nelkin and Brown (1984). They noted that employees depend on their personal efforts to manage occupational safety or health-related issue to work station despite to ask the help or assistance from management or other sources. This is however not the case in construction workers. The study conducted by Dedobbeleer and Beland (1991) on the measurement of safety climate at construction projects observed that construction workers consider safety as a nexus between the workers and organizational management. The safety climate factors suggested by the above two authors, therefore, have only two factors i.e. (i) organizational commitment towards safety and (ii) employees participation. Since the knowledge and understanding of safety climate have widely expanded, therefore considering only management commitment and worker involvement in a 
safety climate assessment tool may not serve the purpose. The limited number factor in this tool was, therefore, one of the main drawbacks, but this doesn't warrant the credibility of these factors. The participation of workers in safety was one of the factors in the safety climate tool developed by the Health and Safety Executive in the UK (HSE, 1997). Workers' participation in safety was further regarded as an important factor in most of the safety climate assessment tools. For instance, the safety climate tool developed by Seo et al. (2004) considered the worker's participation important not only in the safetyrelated matters but also in the decision associated with safety. This factor was continuously considered and placed in the safety climate assessment tools developed in later years (Pousette et al. 2008; CISCIS, 2008; CPWR, 2017).

\subsection{Workers Safety Behavior:}

The current literature around safety and health-related issue suggest that personal factors including noncompliance with safety guideline either by an error or mistake could result into accidents at the workplace (Neal et al. 2000; DeArmond et al. 2011; Umar and Egbu, 2018-a). An important factor to understand that why occupational accidents take place at the workstation is to see the contribution of workplace behavior jointly developed by the group of workers in that place. Fung et al. (2016) in their research on safety awareness of construction workers explored the external factors with the psychological climate that the workers possess on their safety awareness. The model proposed by Umar and Egbu (2018-a) to trace the causes of accidents involves a variety of factors associated directly with workers' behavior. When this model was applied to a highway project to access the causes of accidents in that project, it was revealed that $41 \%$ of the accidents on that project were due to those factors directly linked with the workers. Simulation-Based research conducted by Nasirzadeh et al. (2017) observed that unsafe behavior of different agents is varied throughout the project duration due to the interactions with other agents as well as the safety-related regulations that exist in the site. Campbell et al. (1993) viewed the worker's individual factors such as adherence and compliance of safety procedure, important in safety performance, but these factors are highly influenced by workers' knowledge, skill and ambition. Earlier the model for safety performance proposed by Neal and Griffin (1997) had two factors for safety performance i.e. compliance and participation of workers. The results of a research conducted by Clarke (2006) using the meta-analysis technique, suggested that there is a difference between safety compliance and safety performance. The safety compliance can be referred to as the adherence of organizational safety guidance and performing the work-related task in a safe way. DeArmond et al. (2011) reported that safety behavior may not only contribute to safety performance directly, but it is very helpful to promote a safe working environment when workers participate in meetings and training related to safety.

Recent research exploring the safe behavior concluded that safety attitude, safety knowledge, and supporting the workplace are the main indicators of safety behavior. The improvement in safety attitude and safety knowledge may result in the highest feasible proportion of safety behavior among the workers (Mohammadfam et al., 2017). A recent study conducted by Chan et al. (2017-b) suggests that there is growing evidence that reflects that a large number of ethnic minorities are employed in the construction industry in many countries to meet the labor shortage. The study also suggests that these workers have high fatal and non-fatal injuries rate as compared to local workers. A similar situation of construction workers was also reported by Lyu et al. (2018). Both studies further reveal that perceptions on the safety climate of such workers from ethnic minorities' are significantly varied by nationality, marital status, family members support, and drinking habit. The majority of the workers in GCC countries are from overseas, thus their behavior and safety climate perceptions could be highly affected by factors such as nationality, marital status, family members' support, and drinking habit. The review of safety climate assessment tools reported in table 2, shows that safety behavior directly or indirectly as part of the majority (64\%) of the tools. The worker's safety behavior appears to be an important factor in the safety climate assessment tools, thus needs to be considered part of the safety climate in construction.

\subsection{Safety Communication:}


Generally, frequent communication and interaction with colleagues are mandatory channels to develop or improve social setup including organizational climate. The existing literature suggests that most of the researchers considered communication as a factor that constitutes the organizational climate. For instance, James and James (1989) viewed that organizational climate can be assessed considering the factors related to the individual and or workplace. Similarly, Siew (2015) considered Poor communication on safety and health-related issues as a major cause of incidents/accidents and recognized it as a key challenge to construction practitioners. The general organization's climate can be measured by considering the working environment which may include factors such as leadership, role and communication (James and McIntyre, 1996). There have been a number of studies which concludes that effective safety communication is one of the safety climate factors which can be used to predict the safety performance of a specific organization (Zohar, 1980; Zohar and Luria, 2005; Pousette et al., 2008; Kines et al., 2011). When the organization encourages open communication on safety-related issues, it spread a strong message on how safety is given values in that organization (Hofmann and Stetzer, 1998). Safety communication is therefore not only to be regarded for sharing information, but it is a channel to share ideas and views to help others to learn new things and to incorporate the innovative thought in the existing procedures. Jeffcott et al. (2006) emphasized the learning process to develop a safety culture. They suggested that the collection, analysis, and sharing of relevant data are very important to develop such a culture, where the workers don't hesitate to report their mistakes or error. Workers normally share their mistake or error when they have full trust in the management, thus open and rich communication becomes a more important factor in an organizational safety climate not only for safety performance but also to maintain the trust of their workers (Kines et al., 2011). Safety communication, therefore, should be effective and should be multiway, from management to employees, from employees to the management and among the employees. Similarly, Hale (2000) also emphasized the need for open communication in organizations to improve their safety performance. One of the other aspects of safety communication that is related is the language barrier, which is more important in the Omani construction industry due to its diversity. For instance, the Omani construction industry is heavily populated (92\%) by foreigner workers (Umar and Egbu, 2018-b). These workers belong to different Asian and African countries. These workers have a low educational level and can only speak and understand their native languages. This situation results in similar communication barriers outlined by Gittleman et al. (2010). Construction organizations in Oman, therefore, will have to assess the level of communication barriers first before they can further improve the safety communication in their organizations. This discussion further leads the authors that safety communication is one of the important dimensions of the safety climate and need to be considered in such an assessment.

\subsection{Safety Accountability and Justice:}

It is considered as an important factor that organizations should maintain a fair and just system to deal with the safety-related issues and to ensure that their employees feel no fear to report the errors and mistakes. Reason (1997) while discussing the safety culture, argued that in a mature safe working environment, the workers should be convinced to report the error to their supervisors. Similarly, it is very important the error and mistake either results in an accident or not needs to be dealt properly and the responsibility of such a situation should be fixed carefully as the blame can result in an obstacle in learning (Jeffcott et al. 2006). Similarly, the employees who act unsafely knowing well that his act is unsafe and the employees who act unsafely by mistake should not be considered for the same punishments (Weiner et al. 2008). This can be however challenging to differentiate among such unsafe acts. A just working environment, therefore, needs to base on trust, but there has to be a clear line between acceptable and non-acceptable behavior. Organ (1997) defined organizational citizenship behavior as a volunteer behavior that is very difficult to be recognized by organizations reward procedures, however, such behavior promotes the effective functioning of organizations. He further stated that the workers, who take actively the safety responsibility of their's-selves and others and participate in safety-related activities, display the organizational citizenship behavior. Kines et al. (2011) argued that workers' safety behavior and safety responsibility are positively influenced by the organization's rules and 
procedures which are applicable to safety matters. In other words, an effective just system for dealing with accidents and unsafe acts in an organization will promote safe behavior in workers and will encourage them to accept the responsibility of safety. Recently, Umar and Wamuziri (2017) in their research on the improvement of safety performance using safety climate factors discussed safety justice as an integral factor of constructions' safety climate. They further considered that safety managers in construction organizations need to be accountable for safety expectations through their annual appraisal and performance evaluation. Such factors need to be considered further in their promotion to a higher position, pay rising or renewal of the contract. Overall, the organizations need to provide a fair system which should reflect the accountability and justice for safety. The investigations of the root causes of accidents are compulsory to ensure blame-free accountability. Similarly, the workers need to be rewarded for the exceptional safe act to promote safety and to display a fair system. The review of the safety climate assessment tools discussed in this research reveals that safety accountability and safety justice were among the most common factors considered by several authors in their safety climate assessment tools, which trigger out that such factors need to be considered in the assessment of safety climate of construction organizations or construction projects.

\subsection{Supervisory Leadership:}

The finding of the research conducted by Seo et al, (2004) shows that commitment form management or organization towards safety and support associated with safety from site supervisors are the two main factors used more frequently in the safety climate tools. The role of safety leadership was considered important in the safety performance of the workers by Hofmann and Morgeson (2004). The existing literature on safety climate and safety culture reflects that many researchers reference leadership directly as a key for improved safety. Hofmann and Morgeson (2004) concluded that leadership is further directly linked with other positives results in organization performance, for instance, it can improve and display an effective managerial commitment, production and can reduce absenteeism of workers. In reality, organization leaders have the responsibility to develop a mature culture within the organization that is effective to deliver a safe working environment. Many researchers stressed that supervisors and managers have the initial responsibility to reflect their commitment to safety and such commitment needs to be clearly seen by the workers. For instance, the supervisors and managers are required to take quick actions on matters arise from the accident reports as it is helpful in the development of workers' trust in the management (Mayer et al. 1995; Burns et al. 2006). The literature review suggests that employees' trust in management or organization plays a significant role in developing a safety culture. The results of research conducted by Cox et al. (2006) show that the worker's distrust in management has a negative effect on the effectiveness of the safety culture. Trust in management or organization was viewed so important factor by Kines et al. (2011) that they recommend it to be used in a safety climate assessment tool. The review of the safety climate tools presented in this research shows safety leadership was regarded as an important factor and was used directly or indirectly in these tools. For instance, the safety climate tools developed by Seo et al. (2004) and Center for Protection of Worker's Right (SPWR, 2017) used the supervisory leadership as a main or direct factor in their tools, similarly, the tools developed by Kines et al. (2011) used it indirectly by merging it with the trust in management factor. Generally, supervisory leadership is to be expected to have safety leadership abilities. Similarly, safety leadership in construction is considered as an integral element of supervisory leadership that includes discipline, engagement, values, demonstration, vision and promotion. The research conducted by Umar and Egbu (2018) on safety climate factors in Oman considered the site supervisor role to be an integral part of the safety climate assessment tools. Overall, the above discussion concludes that organization performance is highly linked to supervisory or managerial leadership. The case with safety performance is the same as it is considered to be highly influenced by the supervisors' or mangers' roles and leadership abilities. 


\section{Conclusion:}

Due to the complexity of the construction industry and construction projects, safety remains a major challenge that needs to be addressed. One of the latest approaches to improve safety performance is the safety climate concept which was truly introduced as part of the safety management system during 1980 . Safety climate was defined in a variety of ways by many researchers but in general, it is referred to the share perceptions of workers on different aspects of organizational procedures and protocols related to safety. The terms safety climate and its different dimensions were highly discussed and elaborated in the past 39 years since 1980. This article attempted to review these safety climate factors and make an explicit of the most prevailing factors. A qualitative research method incorporating the internet search spanning over 39 years (1980-2019) was used to identify the leading safety climate factors. After the screening process, a total of 19 safety climate tools with 103 safety climate dimensions were selected for a review in this article. A specific screening process was used to narrow down the results obtained from the internet search. Apart from specifying the period, google citations and industrial applications were considered during the screening process of the results obtained from the internet search. Safety climate tools which were used in construction, oil and gas and utilities sectors were only selected in this article. The PRISMA flow diagram and guidelines were followed to search the existing literature. Finally, the most common safety climate factors including, a) Management or Organizational Commitment towards Safety; b) Safety Training; c) Employees Involvement in Safety; d) Workers Safety Behavior; e) Safety Communication; f) Safety Accountability and Justice and g) Supervisory Leadership, are discussed in more details. These leading safety climate factors can be assessed through a safety climate assessment tool which can be paper-based or electronic-based depending on the capability of organizations and workers. Each safety climate factor will be supported by a number of questions in which respondents will score on a Likert scale of five. The results of such assessment will help the organizations to develop strategies to improve the perceptions of these factors by making short ( 2 months), medium ( 12 months) or long ( 24 months) term plans. For instance, an organization can exemplarily demonstrate the management commitment towards safety by using a number of ideas including; i) Develop safety-related policies, guidelines and procedures which are aligned with organizations that displayed best safety performance; ii) Visit construction site by senior management and adopt appropriate safety behavior; iii) Provide appropriate safety resources; iv) Participation of senior management in safety-related meetings; v) Aim for zero accidents at construction sites. The main limitation of this research is that the common safety climate factors are derived from the published literature only. For a more robust study, it is necessary to validate the results through a questionnaire or interview. This appears a limitation of the study, however, at the same time; this provides room for further research. The study considered a specific period of time $(1980-2019)$ assuming the fact that the terms safety culture and safety climate have attracted the focus of many researchers due to the evolution of human factors in organizations performance, but this does not mean that there could be no study prior to 1980 which focus on factors related to safety culture and safety climate. Most of the studies which are considered in this research were conducted in advanced countries, thus it could be difficult to conclude that the safety climate factors used in these studies could be relevant to the construction in developing countries. The maturity level of the construction industry is different in different countries. For instance, the construction industry in Oman is not that advanced as of the UK. The UK construction industry is highly regulated through different regulatory organizations and regulations such as Health and Safety Executive (HSE), Construction Design and Management (CDM regulations) and Construction Skills Certification Scheme (CSCS). Construction workers in these two countries will have a different interpretation and the importance of a specific safety climate factor may be varied. Thus, it is important to validate the safety climate factors derived in this research before they could be adopted in a specific country or region. The main challenge which is also important and needs to be explored is how small construction organizations with limited resources will be benefitted from the use of a safety climate approach to enhance their safety performance. 


\section{References:}

AIChE (American Institute of Chemical Engineers) (2012) Safety Culture: What Is at Stake? AIChE, New York, NY, USA. See http://www.aiche.org/ccps/topics/elements-processsafety/commitment-process-safety/process-safetyculture/building-safety-culture-toolkit/what-is-at-stake (accessed 01/12/2017).

Alruqi, W.M., Hallowell, M.R. and Techera, U., 2018. Safety climate dimensions and their relationship to construction safety performance: A meta-analytic review. Safety science, 109, pp.165-173. https://doi.org/10.1016/j.ssci.2018.05.019.

Bergh, M., Shahriari, M. and Kines, P., 2013. Occupational safety climate and shift work. Chemical Engineering Transactions, 31(2013): 403 - 408. https://doi.org/10.3303/CET1331068.

Bodner, T., Kraner, M., Bradford, B., Hammer, L., \& Truxillo, D. (2014). Safety, Health, and Well-Being of Municipal Utility and Construction Workers. Journal of Occupational and Environmental Medicine, 56(7), 771-778. https://doi.org/10.1097/jom.0000000000000178.

Bong, S., Rameezdeen, R., Zuo, J., Li, R.Y.M. and Ye, G., 2015. The designer's role in workplace health and safety in the construction industry: post-harmonized regulations in South Australia. International Journal of Construction Management, 15(4), pp.276-287. https://doi.org/10.1080/15623599.2015.1094850.

Bryman, A., 2012. Social research methods, $4^{\text {th }}$ edition. Oxford University Press Inc. New York, USA.

Bryman, A., 2016. Social research methods, $5^{\text {th }}$ edition. Oxford University Press Inc. New York, USA.

Burns, C., Mearns, K. and McGeorge, P., 2006. Explicit and implicit trust within safety culture. Risk Analysis, 26(5), pp.1139-1150. https://doi.org/10.1111/j.1539-6924.2006.00821.x.

Campbell, J.P., McCloy, R.A., Oppler, S.H., Sager, C.E., 1993. A theory of performance. In: Schmitt, J., Borman, W.C. Associates. Personnel Selection in Organizations. Jossey-Bass, San Francisco, CA, USA. pp. 35-69.

Chan, A.P., Javed, A.A., Wong, F.K., Hon, C.K. and Lyu, S., 2017-a. Evaluating the safety climate of ethnic minority construction workers in Hong Kong. Journal of Professional Issues in Engineering Education and Practice, 143(4), p.04017006. https://doi.org/10.1061/(ASCE)EI.1943-5541.0000333.

Chan, A.P., Wong, F.K., Hon, C.K., Lyu, S. and Javed, A.A., 2017-b. Investigating ethnic minorities' perceptions of safety climate in the construction industry. Journal of safety research, 63, pp.9-19. https://doi.org/10.1016/j.jsr.2017.08.006.

Cheyne, A., Cox, S., Oliver, A., Toma's, J.M., 1998. Modelling safety climate in the prediction of levels of safety activity. Work and Stress 12 (3), 255-271. https://doi.org/10.1080/02678379808256865. 
CISCIS (Construction Industry Safety Climate Index Software) 2008. Occupational Safety \& Health Council, Hong Kong, North Point, Hong Kong. See:

https://www.housingauthority.gov.hk/mini-site/site-safety/en/tools/safety-climate-indexsurvey/index.html. (accessed 28/02/2019).

Clarke, S. (2000), Safety culture: underspecified and overrated? International Journal of Management Reviews, 2(1), 65-90. https://doi.org/10.1111/1468-2370.00031.

Clarke, S., 2006. The relationship between safety climate and safety performance: a metaanalytic review. Journal of Occupational Health Psychology 11, 315-327.

Cleveland, R. J., Cohen, H. H., Smith, M. J., \& Cohen, A. Safety program practices in record holding plants. Cincinnati, Ohio: National Institute for Occupational Safety and Health, 1978.

Cohen, A., Smith, M., and Cohen, H. H. Safety program practices in high vs. low accident rate companies - An interim report (U.S. Department of Health, Education and Welfare Publication No. 75-185). Cincinnati, Ohio: National Institute for Occupational Safety and Health, USA. 1975.

Cooper, D.R., Schindler, P.S. and Sun, J., 2006. Business research methods (Vol. 9). New York: McGraw-Hill Irwin. https://trove.nla.gov.au/work/16067972.

Cox, S. and Cox, T., 1991. The structure of employee attitudes to safety: A European example. Work \& stress, 5(2), pp.93-106. https://doi.org/10.1080/02678379108257007.

Cox, S., Jones, B. and Collinson, D., 2006. Trust relations in high-reliability organizations. Risk analysis, 26(5), pp.1123-1138. https://doi.org/10.1111/j.1539-6924.2006.00820.x.

CPWR (2017), The Centre for construction research and training repot 'Strengthening Jobsite Safety Climate', 2017. Maryland, USA. See: http://www.cpwr.com/safetyculture/strengthening-jobsite-safety-climate (accessed: 25/05/2017).

CPWR (Center for Protection of Worker's Right) (2014) The Center for Construction Research and Training Report 'Strengthening Jobsite Safety Climate'. CPWR, Silver Spring, Washington, USA.

DeArmond, S., Smith, A.E., Wilson, C.L., Chen, P.Y. and Cigularov, K.P., 2011. Individual safety performance in the construction industry: Development and validation of two short scales. Accident Analysis \& Prevention, 43(3), pp.948-954. https://doi.org/10.1016/j.aap.2010.11.020.

Dedobbeleer, N. and Béland, F., 1991. A safety climate measure for construction sites. Journal of safety research, 22(2), pp.97-103. https://doi.org/10.1016/0022-4375(91)90017-P.

Flin, R., Mearns, K., O’Connor, P., Bryden, R., 2000. Measuring safety climate: identifying the common features. Safety Science 34 (1e3), 177-192. https://doi.org/10.1016/S09257535(00)00012-6.

Frenkel, R.L., Priest, W.C. and Ashford, N.A., 1980. Occupational safety and health: A report on worker perceptions. Monthly Lab. Rev., 103(11), 11-14. See: https://dspace.mit.edu/bitstream/handle/1721.1/116688/9.\%20occupational\%20safety\%2 0and\%20health\%20worker\%20perceptions.pdf?sequence=1 (accessed: 02/08/2018). 
Fung, I.W., Tam, V.W., Sing, C.P., Tang, K.K.W. and Ogunlana, S.O., 2016. Psychological climate in occupational safety and health: the safety awareness of construction workers in South China. International journal of construction management, 16(4), pp.315-325. https://doi.org/10.1080/15623599.2016.1146114.

Hale AR and Hovden J (1998) Management and culture: the third age of safety. A review of approaches to organizational aspects of safety, health and environment. In Occupational Injury: Risk, Prevention and Intervention (Feyer A-M and Williamson A (eds)). pp. 129227. Taylor \& Francis Ltd., London, UK.

Hale, A.R., 2000. Culture's confusions. Safety Science 34, 1-14.

Hofmann, D.A. and Morgeson, F.P., 2004. The role of leadership in safety. In "The psychology of workplace safety". Edited by Julian Barling and Michael R. Frone. American Psychological Association, Washington, DC, USA. pp.159-180.

Hofmann, D.A., Stetzer, A., 1998. The role of safety climate and communication in accident interpretation: implications for learning from negative events. Academy of Management Journal 41 (6), 644-657. https://doi.org/10.5465/256962.

Hon, C.K., Chan, A.P. and Yam, M.C., 2014-a. Relationships between safety climate and safety performance of building repair, maintenance, minor alteration, and addition (RMAA) works. Safety science, 65, pp.10-19. https://doi.org/10.1016/j.ssci.2013.12.012.

Hon, C.K., Hinze, J. and PC Chan, A., 2014-b. Safety climate and injury occurrence of repair, maintenance, minor alteration and addition works: A comparison of workers, supervisors and managers. Facilities, 32(5/6), pp.188-207. https://doi.org/10.1108/f-09-2011-0066.

HSE, UK (Health and Safety Executive) (1997). Safety Climate Assessment Tool. London, United Kingdom. See: http://www.lboro.ac.uk/departments/sbe/downloads/pmdc/safetyclimate-assessment-toolkit.pdf (accessed 01/07/2017).

ILO (International Labour Organization). 2013. ILO calls for urgent global action to fight occupational diseases. International Labour Organization. Geneva, Switzerland. See: http://www.ilo.org/global/about-the-ilo/newsroom/news/WCMS_211627/lang-en/index.htm (accessed 22/07/2018).

ILO (International Labour Organization); 2015. Construction: a hazardous work. See: http://www.ilo.org/safework/areasofwork/hazardous-work/WCMS_356576/lang-en/index.htm (accessed 11/03/2017).

INSAG (International Nuclear Safety Advisory Group) (1992) INSAG-7: The Chernobyl Accident: Updating of INSAG-1, Safety Series No. 75-INSAG-7. INSAG, Vienna, Austria.

Institute of Work \& Health (2011). Benchmarking Organizational Leading Indicators for the Prevention and Management of Injuries and Illnesses: Final Report. Institute of Work \& Health, Ontario, Canada. See: http://www.iwh.on.ca/benchmarking-organizationalleading-indicators (accessed 30/06/2017).

James, L.A., James, L.R., 1989. Integrating work environment perceptions: Explorations into the measurement of meaning. Journal of Applied Psychology 74, 739-751. 
James, L.R., McIntyre, M.D., 1996. Perceptions of organizational climate. In: Murphy, K. (Ed.), Individual Differences and Behavior in Organizations. Jossey-Bass, San Francisco, CA, pp. 416-450.

Janie L.Gittleman., Paige C.Gardner., ElizabethHaile., Julie M.Sampson., Konstantin P.Cigularov., Erica D.Ermann., PeteStafford., and Peter Y.Chen., 2010. [Case Study] City Center and Cosmopolitan Construction Projects, Las Vegas, Nevada: Lessons learned from the use of multiple sources and mixed methods in a safety needs assessment. Journal of Safety Research Volume 41(3), Pages 263-281. https://doi.org/10.1016/j.jsr.2010.04.004.

Jeffcott, S., Pidgeon, N., Weyman, A., Walls, J., 2006. Risk, trust, and safety culture in UK train operating companies. Risk Analysis 26 (5), 1105-1121. https://doi.org/10.1111/j.15396924.2006.00819.x.

Kalteh, H.O., Mortazavi, S.B., Mohammadi, E. and Salesi, M., 2019. The relationship between safety culture and safety climate and safety performance: a systematic review. International journal of occupational safety and ergonomics, pp.1-11. https://doi.org/10.1080/10803548.2018.1556976.

Kines, P., Lappalainen, J., Mikkelsen, K.L., Olsen, E., Pousette, A., Tharaldsen, J., Tómasson, K. and Törner, M., 2011. Nordic Safety Climate Questionnaire (NOSACQ-50): A new tool for diagnosing occupational safety climate. International Journal of Industrial Ergonomics, 41(6), pp.634-646. https://doi.org/10.1016/j.ergon.2011.08.004.

Lingard, H., Cooke, T. and Blismas, N., 2011. Coworkers' response to occupational health and safety: An overlooked dimension of group-level safety climate in the construction industry?. Engineering, construction and architectural management, 18(2), pp.159-175. https://doi.org/10.1108/09699981111111139.

Lingard, H., Cooke, T. and Blismas, N., 2012. Do perceptions of supervisors' safety responses mediate the relationship between perceptions of the organizational safety climate and incident rates in the construction supply chain?. Journal of Construction Engineering and Management, 138(2), pp.234-241. https://doi.org/10.1061/(asce)co.1943-7862.0000372.

Lingard, H.C., Cooke, T. and Blismas, N., 2010-a. Safety climate in conditions of construction subcontracting: a multi-level analysis. Construction Management and Economics, 28(8), pp.813-825. https://doi.org/10.1080/01446190903480035.

Lingard, H.C., Cooke, T. and Blismas, N., 2010-b. Properties of group safety climate in construction: The development and evaluation of a typology. Construction Management and Economics, 28(10), pp.1099-1112. https://doi.org/10.1080/01446193.2010.501807.

Lyu, S., Hon, C., Chan, A., Wong, F. and Javed, A., 2018. Relationships among safety climate, safety behavior, and safety outcomes for ethnic minority construction workers. International journal of environmental research and public health, 15(3), p.484. https://doi.org/10.3390/ijerph15030484.

Mayer, R.C., Davis, J.H. and Schoorman, F.D., 1995. An integrative model of organizational trust. Academy of management review, 20(3), pp.709-734. https://doi.org/10.5465/amr.1995.9508080335. 
MCR Safety, 2019. An Overview of Construction in Oil and Gas: Rigging Up, Pipeline and Plant Construction Work. MCR Safety, Collierville, Tennessee, United States. See: https://www.mcrsafety.com/blog/an-overview-of-construction-in-oil-and-gas-rigging-uppipeline-and-plant-construction-work (accessed 26/12/2019).

Mohamed, S., 2002. Safety climate in construction site environments. Journal of construction engineering and management, 128(5), pp.375-384. https://doi.org/10.1061/(ASCE)07339364(2002)128:5(375).

Mohammadfam, I., Ghasemi, F., Kalatpour, O. and Moghimbeigi, A., 2017. Constructing a Bayesian network model for improving safety behavior of employees at workplaces. Applied ergonomics, 58, pp.35-47. https://doi.org/10.1016/j.apergo.2016.05.006.

Moher D, Liberati A, Tetzlaff J, Altman DG, Prisma Group. Preferred reporting items for systematic reviews and meta-analyses: the PRISMA statement. PLoS medicine. 2009 Jul 21;6(7):e1000097.

Nasirzadeh, F., Khanzadi, M. and Mir, M., 2018. A hybrid simulation framework for modelling construction projects using agent-based modelling and system dynamics: an application to model construction workers' safety behavior. International Journal of Construction Management, 18(2), pp.132-143. https://doi.org/10.1080/15623599.2017.1285485.

Neal, A. and Griffin, M.A., 1997. Perceptions of Safety at Work: Developing a Model to Link Organizational Safety Climate and Individual Behavior. Paper presented to the 12th Annual Conference of the Society for Industrial and Organizational Psychology, St. Louis, MO. USA.

Neal, A., Griffin, M.A. and Hart, P.M., 2000. The impact of organizational climate on safety climate and individual behavior. Safety science, 34(1), pp.99-109. https://doi.org/10.1016/S0925-7535(00)00008-4.

Nelkin, D., Brown, M. and Brown, M.S., 1984. Workers at risk: Voices from the workplace. University of Chicago Press. Illinois, USA.

NSC (National Safety Council). 1969. Award-winning programs. In, Accident prevention manual for industrial operations (6th ed.). Chicago: Author, 1969.

Opdenakker, R., 2006, September. Advantages and disadvantages of four interview techniques in qualitative research. In Forum Qualitative Sozialforschung/Forum: Qualitative Social Research (Vol. 7, No. 4). http://dx.doi.org/10.17169/fqs-7.4.175.

Organ, D.W., 1997. Organizational citizenship behavior: It's construct clean-up time. Human performance, 10(2), pp.85-97. https://doi.org/10.1207/s15327043hup1002_2.

Parker, D., Lawrie, M. and Hudson, P., 2006. A framework for understanding the development of organisational safety culture. Safety science, 44(6), pp.551-562. https://doi.org/10.1016/j.ssci.2005.10.004.

Pousette, A., Larsson, S. and Törner, M., 2008. Safety climate cross-validation, strength and prediction of safety behaviour. Safety Science, 46(3), pp.398-404. https://doi.org/10.1016/j.ssci.2007.06.016.

Probst, T.M., Goldenhar, L.M., Byrd, J.L. and Betit, E., 2019. The safety climate assessment tool (s-cat): A rubric-based approach to measuring construction safety climate. Journal of Safety Research, 69, pp.43-51. https://doi.org/10.1016/j.jsr.2019.02.004. 
Reason, J., 1997. Managing the Risks of Organizational Accidents. Ashgate Publishing Limited, Aldershot. UK.

Roth, P., BeVier, C., 1998. Response rates in HRM/OB survey research: norms and correlates, 1990-1994. Journal of Management 24, 97-117. https://doi.org/10.1177\%2F014920639802400107.

Schwatka, N.V., Hecker, S. and Goldenhar, L.M., 2016. Defining and measuring safety climate: a review of the construction industry literature. Annals of occupational hygiene, 60(5), pp.537-550. https://doi.org/10.1093/annhyg/mew020.

Seo, D.C., Torabi, M.R., Blair, E.H., Ellis, N.T. (2004), A cross-validation of safety climate scale using confirmatory factor analytic approach. Journal of Safety Research 35 (4), 427-445. https://doi.org/10.1016/j.jsr.2004.04.006.

Shafai-Sahrai, Y. An inquiry into factors that might explain differences in occupational accident experience of similar size firms in the same industry (Tech. rep.). East Lansing, Mich.: Division of Research, Graduate School of Business Administration, Michigan State University Press, Michigan, USA. 1971.

Siew, R.Y., 2015. Health and safety communication strategy in a Malaysian construction company: a case study. International Journal of Construction Management, 15(4), pp.310-320. https://doi.org/10.1080/15623599.2015.1084469.

Statista, 2017. Construction industry spending worldwide from 2014 to 2025 (in trillion U.S. dollars). Statista, Inc. New York, USA. See: https://www.statista.com/statistics/788128/construction-spending-worldwide/ (accessed 24/04/2018).

Umar T and Wamuziri S (2016) A review of construction safety, challenges and opportunities Oman perspective. In Proceedings of 5th World Construction Symposium, Colombo, Sri Lanka (Sandanayake YG, Karunasena GI and Ramachandra T (eds)). University of Moratuwa, Colombo, Sri Lanka, pp. 14-22.

Umar, T. and Egbu, C., 2018. Perceptions on safety climate: a case study in the Omani construction industry. Proceedings of the Institution of Civil Engineers-Management, Procurement and Law. 171(6): pp. 251 - 263. https://doi.org/10.1680/jmapl.18.00001.

Umar, T. and Egbu, C., 2018-a. Causes of construction accidents in Oman. Middle East Journal of Management, 5(1), pp.21-33. https://doi.org/10.1504/MEJM.2018.088725.

Umar, T. and Egbu, C., 2018-b. Heat Stress, a Hidden Cause of Accidents in Construction. Proceedings of the Institution of Civil Engineers-Municipal Engineer (pp. 1-30). Thomas Telford Ltd. https://doi.org/10.1680/jmuen.18.00004.

Umar, T. and Wamuziri, S., 2017. Using 'safety climate factors' to improve construction safety. Proceedings of the Institution of Civil Engineers: Municipal Engineer (Vol. 170, No. 2, pp. 65-67). Thomas Telford Ltd. https://doi.org/10.1680/jmuen.16.00020.

Umar, T., 2016. Cost of accidents in the construction industry of Oman. Proceedings of the Institution of Civil Engineers-Municipal Engineer (Vol. 170, No. 2, pp. 68-73). Thomas Telford Ltd. https://doi.org/10.1680/jmuen.16.00032.

Umar, T., 2018. Causes of delay in construction projects in Oman. Middle East Journal of Management, 5(2), pp.121-136. https://doi.org/10.1504/MEJM.2018.091132. 
Umar, T., Egbu, C. and Saidani, M., 2019. A Modified Method for Los Angeles Abrasion Test. Iranian Journal of Science and Technology, Transactions of Civil Engineering, pp.1-7. https://doi.org/10.1007/s40996-019-00268-w.

Umar, T., Egbu, C., Wamuzir, S. and Honnurvali, M.S., 2018. Occupational Safety and Health Regulations in Oman. Proceedings of the Institution of Civil Engineers: Management, Procurement and Law. 171(3), pp.93-99. https://doi.org/10.1680/jmapl.18.00007.

Ventures, 2018. US\$ 29.4 Bn worth of contracts awarded in GCC in Q1, 2018. Ventures Onsite, Ventures Middle East DMCC; Dubai, United Arab Emirates. See: http://venturesmiddleeast71550.activehosted.com/index.php?action=social\&chash=1c383 cd30b7c298ab50293adfecb7b18.70 (accessed 25/04/2018).

Walter, V., \& Haines, T. (1988). Workers' perceptions, knowledge and responses regarding occupational health and safety: A report on a Canadian study. Social Science and Medicine, 27 (II), 1189-1196. https://doi.org/10.1016/0277-9536(88)90348-6.

Weiner, B.J., Hobgood, C. and Lewis, M.A., 2008. The meaning of justice in safety incident reporting. Social science \& medicine, 66(2), pp.403-413. https://doi.org/10.1016/j.socscimed.2007.08.013.

Zahoor, H., Chan, A.P., Masood, R., Choudhry, R.M., Javed, A.A. and Utama, W.P., 2016. Occupational safety and health performance in the Pakistani construction industry: stakeholders' perspective. International Journal of Construction Management, 16(3), pp.209-219. https://doi.org/10.1080/15623599.2015.1138027.

Zohar, D. and Luria, G., 2005. A multilevel model of safety climate: cross-level relationships between organization and group-level climates. Journal of applied psychology, 90(4), p.616. http://psycnet.apa.org/doi/10.1037/0021-9010.90.4.616.

Zohar, D., 1980. Safety climate in industrial organizations: theoretical and applied implications. Journal of applied psychology, 65(1), p.96. http://psycnet.apa.org/doi/10.1037/00219010.65.1.96. 